\title{
Age, gender, quadriceps strength and hop test performance are the most important factors affecting the achievement of a patient-acceptable symptom state after $\mathrm{ACL}$ reconstruction
}

\author{
Riccardo Cristiani $^{1,2} \mathbb{D} \cdot$ Christina Mikkelsen ${ }^{1,2} \cdot$ Gunnar Edman $^{1} \cdot$ Magnus Forssblad $^{1} \cdot$ Björn Engström $^{1,2} \cdot$ \\ Anders Stålman ${ }^{1,2}$
}

Received: 6 February 2019 / Accepted: 17 June 2019 / Published online: 22 June 2019

(c) The Author(s) 2019

\begin{abstract}
Purpose To assess the percentage of patients achieving an acceptable symptom state 2 years after primary anterior cruciate ligament reconstruction (ACLR) and to identify factors affecting its achievement, in a large cohort.

Methods Patients who underwent primary ACLR at Capio Artro Clinic, Stockholm, Sweden, from 2005 to 2015, were identified in our clinic registry. Patients who had completed the Knee injury and Osteoarthritis Outcome Score (KOOS) at the 2-year follow-up were included. The primary outcome was the achievement of a patient-acceptable symptom state (PASS) for each KOOS subscale. A multivariate logistic regression analysis was used to determine whether patient age, gender, time from injury to surgery, pre-injury Tegner activity level, graft type, cartilage injury, the presence of medial meniscus (MM) or lateral meniscus (LM) resection or repair and the recovery of 6-month symmetrical (limb symmetry index [LSI] of $\geq 90 \%$ ) isokinetic quadriceps or hamstring strength and single-leg-hop test performance were factors associated with the achievement of a PASS for each KOOS subscale.

Results A total of 2335 primary ACLRs were included. More than $60 \%$ of the patients reported a PASS on four of the five KOOS subscales. Age $\geq 30$ years and an LSI of $\geq 90 \%$ for 6-month isokinetic quadriceps strength increased the odds of achieving a PASS across all KOOS subscales. Female gender reduced the odds of achieving a PASS on the Pain (OR 0.76; 95\% CI $0.62-0.94 ; P=0.01)$, activities of daily living (ADL) (OR 0.79; 95\% CI 0.64-0.97; $P=0.02)$ and sport and recreation (OR $0.72 ; 95 \%$ CI $0.58-0.89 ; P=0.003$ ) subscales. The presence of an MM repair reduced the odds of achieving a PASS on the Pain (OR 0.59; 95\% CI 0.36-0.96; $P=0.03$ ) subscale. Hamstring tendon (HT) autograft rather than bone-patellar tendon-bone (BPTB) autograft showed increased odds (OR 2.02; 95\% CI 1.31-3.10; $P=0.001$ ), whereas a cartilage injury showed reduced odds (OR 0.73; 95\% CI 0.55-0.97; $P=0.03$ ) of achieving a PASS on the sport and recreation subscale. An LSI of $\geq 90 \%$ for 6-month single-leg-hop test performance increased the odds of achieving a PASS on the ADL (OR 1.37; 95\% CI 1.09-1.71; $P=0.005$ ), Sport and Recreation (OR 1.40; 95\% CI 1.11-1.77; $P=0.004$ ), and quality of life (OR 1.28; 95\% CI 1.00-1.63; $P=0.04)$ subscales.

Conclusion More than $60 \%$ of the patients reported an acceptable symptom state on four of the five KOOS subscales 2 years after primary ACLR. Age $\geq 30$ years and female gender were the non-modifiable factors that consistently increased and reduced, respectively, the odds of achieving a PASS. A symmetrical 6-month isokinetic quadriceps strength and single-leghop test performance were the modifiable factors that consistently increased the opportunity of achieving a PASS 2 years after primary ACLR.
\end{abstract}

Level of evidence III.

Keywords Anterior cruciate ligament - ACL reconstruction · KOOS · Subjective knee function · Rehabilitation · Quadriceps strength · Single-leg-hop test

Riccardo Cristiani

riccardo.cristiani87@gmail.com

Extended author information available on the last page of the article 


\section{Introduction}

Patient-reported outcomes (PROs) are essential in clinical research, as they measure the patient's perception of treatment. The Knee injury and Osteoarthritis Outcome Score (KOOS) [34] is a PRO that is consistently reported in the literature to measure subjective knee function after anterior cruciate ligament (ACL) reconstruction (ACLR) [4, 8, 9, $16,20,37]$. However, the interpretability of the KOOS is not straightforward. An absolute post-operative score that might be regarded as successful by the clinician may not correspond to a patient's satisfactory knee function [27]. Recently, Muller et al. [27] established, for each KOOS subscale, the threshold values for the achievement of a patientacceptable symptom state (PASS) from 1 to 5 years after primary ACLR. These values were defined by answering the question: "Taking into account all the activity you have during your daily life, your level of pain, and also your activity limitations and participation restrictions, do you consider the current state of your knee satisfactory?". The establishment of post-operative KOOS values corresponding to "feeling well" from the patient's own perception of treatment and identified with the achievement of a PASS may facilitate the interpretation of the KOOS after ACLR.

A variety of factors may affect the achievement of a PASS after ACLR and current knowledge regarding these factors is limited. The heterogeneity of patients' pre-operative, intraoperative and post-operative variables makes it difficult to predict which patients will be able to achieve a PASS after primary ACLR. However, knowledge of the factors affecting the achievement of a PASS after ACLR is important. First, this information would be very valuable to counsel and advise patients about their future expectations. Moreover, if any of these factors is modifiable, this gives us the opportunity to make changes to our treatment plan with an anticipated improved outcome. A full understanding of the factors affecting the achievement of a PASS after primary ACLR, therefore, allows us to personalise and maximise our patient care. To date, no previous studies have assessed the rate of patients achieving a PASS after primary ACLR in a large cohort. In addition, a detailed analysis of the patient factors affecting its achievement has not previously been presented.

The purpose of this study was to assess the percentage of patients achieving a PASS 2 years after primary ACLR and, moreover, to identify pre-operative, intra-operative, and post-operative factors affecting its achievement, in a large cohort. The hypothesis was that age, gender, graft choice, concomitant meniscal surgery, or cartilage injuries and the recovery of 6-month symmetrical isokinetic quadriceps or hamstring strength and single-leg-hop test performance would affect the achievement of a PASS 2 years after primary ACLR.

\section{Materials and methods}

A total of 5231 patients who underwent primary ACLR at Capio Artro Clinic, Stockholm, Sweden, from 2005 to 2015, with no concomitant ligament injuries, were identified. The exclusion criteria were contralateral ACL injuries or reconstruction $(n=227)$ and revision ACLR $(n=210)$ during the follow-up. A cohort of 4794 patients was thus eligible for inclusion in the study. From this cohort, 2459 patients $(51.3 \%)$ were excluded due to no KOOS data at the 2-year follow-up.

\section{Surgical technique and rehabilitation}

All the patients underwent surgery using a single-bundle autologous hamstring tendon (HT) or bone-patellar tendonbone (BPTB) technique. For the ACLRs performed with HT graft, the semitendinosus tendon was primarily harvested and prepared as a triple or quadruple graft. If the length or the diameter of the graft was considered insufficient $(<8 \mathrm{~mm})$, the gracilis tendon was additionally harvested and combined with the semitendinosus graft. The BPTB graft was harvested as the central third of the patellar tendon with two bone blocks. The femoral tunnel was drilled using an anteromedial portal technique. Both grafts were routinely fixed using an Endobutton fixation device (Smith \& Nephew, Andover, Mass, USA) on the femoral side and Ethibond no. 2 sutures (Ethicon, Sommerville, NJ) tied over an AO bicortical screw with a washer as a post or using an interference screw on the tibial side. Meniscal repair was performed, for both the medial meniscus (MM) and lateral meniscus (LM), with an arthroscopic all-inside technique, using a Fast-Fix suture anchor device (Smith and Nephew, Andover, Mass, USA), or an inside-out technique for tears located in the dorsal and middle portion of the meniscus. An outside-in technique was used for tears located in the anterior portion of the meniscus. Both inside-out and outside-in meniscal repair techniques were performed using PDS 0 (Ethicon, Sommerville, NJ). All the patients followed a standardised postoperative rehabilitation protocol. In the event of an isolated ACLR or ACLR with simultaneous meniscal resection, full weight bearing and full range of motion were encouraged as tolerated. If meniscal repair was performed, patients wore a hinged knee brace for 6 weeks. Flexion was limited from $0^{\circ}$ to $30^{\circ}$ for the first 2 weeks, from $0^{\circ}$ to $60^{\circ}$ for the third and fourth weeks and from $0^{\circ}$ to $90^{\circ}$ for the fifth and sixth weeks after surgery. Starting from the seventh week, the knee brace was discontinued and progressive weight bearing was allowed. The early rehabilitation phase focused on regaining range of motion, reducing swelling, and correcting gait. The rehabilitation protocol included joint and muscle flexibility exercises, balance/coordination training, and 
strength training, focusing primarily on the thigh muscles. For all patients, quadriceps strengthening was restricted to closed kinetic chain exercises during the first 3 months. On the basis of muscle strength, coordination, hop performance, and sport practised, the patients were allowed to return to sports 6 months post-operatively at the earliest.

\section{Isokinetic strength and single-leg-hop test performance assessment}

The patients underwent isokinetic strength and single-leghop test performance assessment using a standardised protocol 6 months post-operatively.

Isokinetic concentric quadriceps and hamstring strength were measured bilaterally at $90 \%$ s using the Biodex System 3 (Biodex Medical Systems, Shirley, New York, USA). The test was performed in a range of motion between $90^{\circ}$ and $10^{\circ}$ of knee flexion, always starting with the contralateral uninjured knee. Prior to the test, the patients warmed up using a stationary cycling ergometer at low resistance for $10 \mathrm{~min}$. Patients were given a verbal description of the test and twoto-three practical trials were allowed before testing. Each patient performed five maximum quadriceps and hamstring contractions with each leg. Patients were verbally encouraged during the test. The peak quadriceps and hamstring torque values (highest achieved values) were registered.

The single-leg-hop test was used to assess functional hop performance $[31,35]$. The test was performed with the patient standing on one leg and being instructed to jump straight ahead as far as possible and land on the same leg. The test was considered successful if the landing was stable. If the patient landed with an early touchdown of the contralateral limb, which had loss of balance or took additional hops after landing, the hop was repeated. Patients were initially given a verbal description of the test and they were allowed to perform as many practical trials as they wanted, until they felt confident about the test. Three trials were performed for each leg, always starting with the contralateral uninjured leg. Patients were given as much time as they wanted between the trials to minimise fatigue. The best trial for each leg was registered.

The achievement of a symmetrical [limb symmetry index (LSI)] isokinetic quadriceps and hamstring strength or single-leg-hop test performance was defined as performing at least $90 \%$ of the uninvolved limb (LSI $\geq 90 \%$ ) for each test $[13,29,44]$.

\section{Data sources}

Demographic data (age and gender), information about the time from injury to surgery, pre-injury Tegner activity level [43], graft type, meniscus surgery, the presence of cartilage injuries, and the results of the isokinetic quadriceps and hamstring strength tests and single-leg-hop test 6 months after ACLR were collected in our clinic registry. Meniscus surgery was classified as follows: no meniscus surgery, meniscus resection, or meniscus repair for both the medial and lateral meniscus. The results of the KOOS at the 2-year follow-up were reviewed.

\section{Outcome}

The primary outcome of the study was the achievement of a PASS for each KOOS subscale [27] 2 years after ACLR. The KOOS is a frequently used disease-specific PRO for measuring functional knee outcome in patients undergoing ACLR. It is divided into five subscales: Pain, Knee-related Symptoms, Activities of Daily Living (ADL), Sport and Recreation, and Knee-related Quality of Life (QoL). The Sport and Recreation and QoL subscales have been reported by Roos et al. [34] to be the most responsive at a post-operative follow-up after ACLR.

Each subscale is scored from 0 , representing "extreme knee problems", to 100 , representing "no knee problems". It is recommended to evaluate the individual subscales independently [34]. The achievement of a PASS on the KOOS was assessed on the basis of the threshold values identified by Muller et al. [27]. The corresponding PASS values for the KOOS subscales were as follows: pain $\geq 88.9$; symptoms $\geq 57.1 ; \mathrm{ADL}=100$; sport and recreation $\geq 75.0$; and QoL $\geq 62.5$.

Ethical approval for this study was obtained from the regional ethics committee, Karolinska Institutet (Diarienumber 2016/1613-31/32).

\section{Statistical analysis}

The Statistical Package for Social Sciences, SPSS (Version 25.0, IBM Corp., Armonk, New York, USA), was used for the statistics. All the variables were summarised with the standard descriptive statistics such as the mean, standard deviations (SD), or frequency. The distributions were checked for severe skewness $(>1.5)$ and outliers. To compare the included (with 2-year KOOS data) and the excluded (with no 2-year KOOS data) patients (dropout analysis), Pearson's Chi-square test was used.

The achievement of a PASS for each KOOS subscale was used separately as outcome measurement. Multivariate logistic regression analyses were performed with age, gender (female vs. male), time from injury to surgery (delayed $>3$ months vs. not delayed $\leq 3$ months), pre-injury Tegner activity level (high $\geq 6$ vs. low $<6$ ), graft (HT vs. BPTB autograft), medial meniscus resection, medial meniscus repair, lateral meniscus resection, lateral meniscus repair, cartilage injury and the recovery of 6-month symmetrical (LSI $\geq 90 \%$ ) isokinetic quadriceps strength, 
hamstring strength, and single-leg-hop test performance as independent variables, and the achievement of a PASS on each KOOS subscale as the dependent variable. Age was dichotomized into classes close to the median $(\geq 30$ years vs. $<30$ years). The results of the logistic regression analyses were expressed as odds ratios (OR) with $95 \%$ confidence intervals (CI). The level of significance in all analyses was $5 \%$ (two-tailed).

Provided that there was a significance level of $5 \%$, a power of $85 \%$, and a sample size of more than 1000 patients, even a very weak relationship of less than 0.10 (phi coefficient), which corresponds to an effect size of less than 0.10 , according to Cohen, would be detected.

\section{Results}

A total of 2335 patients fulfilled the inclusion criteria with a complete 2-year post-operative follow-up for all the KOOS subscales. The percentage of 2-year KOOS outcome follow-up was $48.7 \%$ (2335/4794). A comparison between the included cohort and the cohort with no 2-year KOOS data (dropout analysis) is detailed in Table 1. Patients with no 2 -year KOOS data were significantly younger $(P<0.001)$. Although the difference in mean age between the groups was only 1.4 years, the patients in the included cohort were more likely to be 30 years old or older in comparison to patients with no 2-year KOOS data (47.2\% vs. $40.1 \%)$. In addition, men were significantly more likely than women to be lost to follow-up $(<0.001)$. Female patients were significantly more represented in the included cohort in comparison to the cohort with no 2 -year KOOS data (49.4\% vs. $38.7 \%$ ). The number of patients with a concomitant lateral meniscus resection was slightly lower in the included cohort in comparison to the excluded cohort $(13.9 \%$ vs. $16.1 \% ; P<0.04)$. Meanwhile, no significant differences were found between the cohorts with regard to all the other variables (Table 1).

The 2-year mean KOOS values and the rate of PASS for each dichotomized patient group in the included cohort are detailed in Table 2.

The proportion of patients achieving a PASS varied between the KOOS subscales as follows: pain 68.3\%; symptoms $93.6 \%$; ADL 45.6\%; sport and recreation $62.6 \%$; and QoL 69.0\%.

Age $\geq 30$ years and an LSI of $\geq 90 \%$ for 6-month isokinetic quadriceps strength increased the odds of achieving a PASS across all KOOS subscales. Female gender reduced the odds of achieving a PASS on the Pain, ADL, and Sport and Recreation subscales. The presence of an MM repair reduced the odds of achieving a PASS on the Pain subscale. The use of HT autograft rather than BPTB autograft showed increased odds, whereas a cartilage injury showed reduced odds of achieving a PASS on the Sport and Recreation subscale. An LSI of $\geq 90 \%$ for 6-month single-leg-hop test performance increased the odds of achieving a PASS on the ADL, Sport and Recreation, and QoL subscales. No other factors were found to be associated with the achievement of a PASS on the KOOS subscales 2 years after ACLR (Tables 3, 4, 5, 6, and 7).

\section{Discussion}

The main finding of this study was that the proportion of patients achieving a PASS (i.e., "feeling well") 2 years after ACLR varied substantially between the KOOS subscales, from $45.6 \%$ for the ADL subscale to $93.6 \%$ for the Symptoms subscale. However, more than $60 \%$ of the patients reported a PASS on four of the five KOOS subscales. The largest effect on predicting the achievement of a PASS on the different KOOS subscales 2 years after ACLR was found for age, gender, and the recovery of 6-month symmetrical isokinetic quadriceps strength and single-leg-hop test performance. Older age ( $\geq 30$ years) consistently increased the odds of achieving a PASS across all KOOS subscales, whereas female gender reduced the odds of achieving a PASS on the Pain, ADL, and Sport and Recreation subscales. The recovery of 6-month symmetrical isokinetic quadriceps strength increased the odds of achieving a PASS on all KOOS subscales and a symmetrical 6-month singleleg-hop test performance increased the odds of achieving a PASS on the ADL, Sport and Recreation, and QoL subscales 2 years after ACLR.

The previous studies have investigated the effect of age on subjective knee function, measured with the KOOS, after primary ACLR $[1,9,12]$. However, they reported conflicting results. Ageberg et al. [1] found that, at 2 years postoperatively, age did not influence the KOOS scores. Hamrin Senorski et al. [12], in a recent study based on 343 patients, found that younger age at reconstruction results in favourable odds of achieving a PASS across the KOOS subscales 1 year after ACLR. On the other hand, Desai et al. [9], in a previous, larger study based on the Swedish national knee ligament registry, showed that older age is associated with better subjective knee function, measured with the KOOS, after ACLR. Our study confirms these findings, showing that age $\geq 30$ years consistently increases the odds of achieving a PASS across all the KOOS subscales. Younger patients ( $<30$ years) could constitute a more active population, more likely to expose their knees to loads and activities requiring high function. As a result, they might not be completely satisfied more frequently after surgery, reporting a lower KOOS [9] and reducing the odds of achieving a PASS post-operatively.

Several studies have reported inferior outcomes for females after ACLR [1, 9, 12, 42]. Ageberg et al. [1] showed 
Table 1 Patient characteristics and dropout analysis

\begin{tabular}{|c|c|c|c|}
\hline & Included cohort $(n=2335)$ & No 2-year KOOS data $(n=2459)$ & $P$ value \\
\hline \multicolumn{4}{|l|}{ Pre-operative factors } \\
\hline Age at surgery, years, mean \pm SD & $29.7 \pm 10.9$ & $28.3 \pm 9.9$ & $<0.001$ \\
\hline Age younger than 30 years & $20.9 \pm 4.6 ; 1233(52.8)$ & $21.4 \pm 4.6 ; 1475(59.9)$ & \\
\hline Age 30 years or older & $39.5 \pm 6.7 ; 1102(47.2)$ & $38.5 \pm 6.4 ; 984(40.1)$ & \\
\hline Gender & & & $<0.001$ \\
\hline Male & $1182(50.6)$ & $1508(61.3)$ & \\
\hline Female & $1153(49.4)$ & $951(38.7)$ & \\
\hline Time from injury to surgery, months, mean \pm SD & $15.1 \pm 8.7$ & $16.9 \pm 9.8$ & n.s. \\
\hline$\leq 3$ months & $381(17.7)$ & $352(16.2)$ & \\
\hline \multirow[t]{2}{*}{$>3$ months } & $1769(82.3)$ & $1821(83.8)$ & \\
\hline & $n=2150$ & $n=2173$ & \\
\hline Pre-injury Tegner activity level, median (range) & $7(1-10)$ & $7(1-10)$ & n.s. \\
\hline High, $\geq 6$ & $1749(87.4)$ & $1897(89.1)$ & \\
\hline \multirow[t]{2}{*}{ Low, $<6$} & $252(12.6)$ & $232(10.9)$ & \\
\hline & $n=2001$ & $n=2129$ & \\
\hline \multicolumn{4}{|l|}{ Intra-operative factors } \\
\hline Graft type & & & n.s. \\
\hline HT autograft & $2100(89.9)$ & $2182(88.7)$ & \\
\hline BPTB autograft & $235(10.1)$ & $277(11.3)$ & \\
\hline No meniscus surgery & $1528(65.4)$ & $1473(59.9)$ & \\
\hline \multicolumn{4}{|l|}{ Medial meniscus surgery } \\
\hline Resection & $321(13.7)$ & $379(15.4)$ & n.s. \\
\hline Repair & $95(4.0)$ & $128(5.2)$ & n.s. \\
\hline \multicolumn{4}{|l|}{ Lateral meniscus surgery } \\
\hline Resection & $326(13.9)$ & $395(16.1)$ & 0.04 \\
\hline Repair & $65(2.8)$ & $84(3.4)$ & n.s. \\
\hline Cartilage injury & & & n.s. \\
\hline Yes & $469(20.0)$ & $478(19.4)$ & \\
\hline No & $1866(80.0)$ & $1981(80.6)$ & \\
\hline \multicolumn{4}{|l|}{ Post-operative factors (6 months) } \\
\hline Isokinetic quadriceps strength & & & n.s. \\
\hline LSI $\geq 90 \%$ & $758(32.5)$ & $713(34.3)$ & \\
\hline \multirow[t]{2}{*}{ LSI $<90 \%$} & $1575(67.5)$ & $1367(65.7)$ & \\
\hline & $n=2333$ & $n=2080$ & \\
\hline Isokinetic hamstring strength & & & n.s. \\
\hline $\mathrm{LSI} \geq 90 \%$ & $1120(48.0)$ & $963(46.3)$ & \\
\hline \multirow[t]{2}{*}{ LSI $<90 \%$} & $1210(52.0)$ & $1115(53.7)$ & \\
\hline & $n=2330$ & $n=2078$ & \\
\hline Single-leg-hop test & & & n.s. \\
\hline LSI $\geq 90 \%$ & $1335(65.5)$ & $1210(66.9)$ & \\
\hline \multirow[t]{2}{*}{ LSI $<90 \%$} & $704(34.5)$ & $596(33.1)$ & \\
\hline & $n=2039$ & $n=1806$ & \\
\hline
\end{tabular}

Data are reported as $n(\%)$, unless otherwise indicated

KOOS Knee injury and Osteoarthritis Outcome Score; SD standard deviation; HT hamstring tendon; BPTB bone-patellar tendon bone; $L S I$ limb symmetry index

that female patients report poorer scores than male patients on the KOOS Sport and Recreation and KOOS QoL, at 2 years post-operatively. They hypothesised that one possible reason for female patients reporting poorer outcomes than male patients might be differences in muscle function. However, the effect of muscle function, expressed as symmetrical 
Table 2 Mean \pm SD (PASS \%) KOOS values for each dichotomized patient group in the included cohort ( $n=2335$ patients) at the 2 -year followup

Pain (PASS $\geq 88.9) \quad$ Symptoms $($ PASS $\geq 57.1) \quad$ ADL $(P A S S=100) \quad$ Sport and recrea- $\quad$ QoL $($ PASS $\geq 62.5)$ tion (PASS $\geq 75.0)$

\begin{tabular}{|c|c|c|c|c|c|}
\hline \multicolumn{6}{|l|}{ Pre-operative factors } \\
\hline \multicolumn{6}{|l|}{ Age at surgery } \\
\hline Age younger than 30 years & $87.9 \pm 13.9(56.4)$ & $81.4 \pm 16.5(92.3)$ & $94.2 \pm 10.9(44.6)$ & $73.4 \pm 24.5(61.3)$ & $65.6 \pm 23.8(64.5)$ \\
\hline Age 30 years or older & $90.3 \pm 12.3(64.0)$ & $85.4 \pm 14.4(95.2)$ & $94.5 \pm 10.4(46.7)$ & $74.9 \pm 24.7(64.3)$ & $71.0 \pm 21.4(74.1)$ \\
\hline \multicolumn{6}{|l|}{ Gender } \\
\hline Male & $89.9 \pm 13.2(71.5)$ & $83.6 \pm 15.9(93.8)$ & $94.5 \pm 10.9(49.0)$ & $76.3 \pm 23.5(66.3)$ & $69.4 \pm 23.3(70.6)$ \\
\hline Female & $88.1 \pm 13.2(65.0)$ & $82.9 \pm 15.4(93.6)$ & $94.2 \pm 10.4(42.1)$ & $71.8 \pm 25.5(59.0)$ & $66.8 \pm 22.4(67.4)$ \\
\hline \multicolumn{6}{|l|}{ Time from injury to surgery } \\
\hline$\leq 3$ months & $89.0 \pm 13.1(69.1)$ & $82.3 \pm 16.5(92.8)$ & $94.6 \pm 10.6(48.8)$ & $74.8 \pm 24.5(64.2)$ & $68.1 \pm 23.2(69.7)$ \\
\hline$>3$ months & $89.0 \pm 13.2(67.9)$ & $83.6 \pm 15.4(94.0)$ & $94.3 \pm 10.7(44.5)$ & $73.9 \pm 24.7(62.2)$ & $68.2 \pm 22.8(68.8)$ \\
\hline \multicolumn{6}{|l|}{ Pre-injury Tegner activity level } \\
\hline High $\geq 6$ & $89.0 \pm 13.0(67.8)$ & $83.0 \pm 15.7(93.4)$ & $94.5 \pm 10.3(45.4)$ & $74.6 \pm 24.0(62.9)$ & $68.1 \pm 22.7(68.9)$ \\
\hline Low $<6$ & $89.0 \pm 13.7(69.6)$ & $83.9 \pm 15.0(94.2)$ & $94.0 \pm 11.6(46.2)$ & $72.8 \pm 26.3(61.2)$ & $68.3 \pm 23.4(69.4)$ \\
\hline \multicolumn{6}{|l|}{ Intra-operative factors } \\
\hline \multicolumn{6}{|l|}{ Graft type } \\
\hline HT autograft & $89.2 \pm 12.8(68.5)$ & $83.4 \pm 15.0(93.7)$ & $94.5 \pm 10.3(45.1)$ & $74.7 \pm 24.2(63.4)$ & $68.5 \pm 22.5(69.4)$ \\
\hline BPTB autograft & $87.5 \pm 16.0(65.9)$ & $82.1 \pm 18.1(92.3)$ & $93.1 \pm 13.6(49.8)$ & $69.0 \pm 28.0(56.1)$ & $65.0 \pm 25.8(65.5)$ \\
\hline No meniscus surgery & $89.1 \pm 13.0(68.6)$ & $83.6 \pm 15.6(93.8)$ & $94.4 \pm 10.5(45.7)$ & $74.2 \pm 24.6(62.5)$ & $68.5 \pm 23.0(70.3)$ \\
\hline \multicolumn{6}{|l|}{ Medial meniscus surgery } \\
\hline Resection & $89.9 \pm 14.0(73.2)$ & $85.0 \pm 13.8(96.2)$ & $94.6 \pm 11.5(49.2)$ & $75.8 \pm 23.8(66.7)$ & $69.8 \pm 21.7(71.0)$ \\
\hline Repair & $85.3 \pm 14.0(54.7)$ & $78.0 \pm 16.5(88.4)$ & $93.4 \pm 10.9(37.8)$ & $68.0 \pm 27.6(55.8)$ & $62.3 \pm 23.4(57.9)$ \\
\hline \multicolumn{6}{|l|}{ Lateral meniscus surgery } \\
\hline Resection & $89.0 \pm 14.0(66.6)$ & $82.4 \pm 16.2(92.3)$ & $93.9 \pm 12.5(43.9)$ & $74.3 \pm 24.1(63.8)$ & $67.9 \pm 23.0(67.8)$ \\
\hline Repair & $87.9 \pm 13.0(66.2)$ & $79.2 \pm 20.0(87.6)$ & $96.3 \pm 6.1(50.7)$ & $73.7 \pm 26.5(64.6)$ & $67.5 \pm 23.1(64.6)$ \\
\hline \multicolumn{6}{|l|}{ Cartilage injury } \\
\hline Yes & $89.2 \pm 12.0(68.0)$ & $82.9 \pm 15.3(93.6)$ & $94.1 \pm 10.2(42.2)$ & $72.3 \pm 25.7(59.3)$ & $68.1 \pm 22.4(69.1)$ \\
\hline No & $89.0 \pm 13.0(68.4)$ & $83.4 \pm 15.8(93.7)$ & $94.4 \pm 10.8(46.1)$ & $74.5 \pm 24.3(63.6)$ & $68.2 \pm 23.0(69.1)$ \\
\hline \multicolumn{6}{|c|}{ Post-operative factors (6 months) } \\
\hline \multicolumn{6}{|l|}{ Isokinetic quadriceps strength } \\
\hline $\mathrm{LSI} \geq 90 \%$ & $90.3 \pm 12.6(73.6)$ & $85.3 \pm 15.0(95.4)$ & $95.6 \pm 9.5(51.7)$ & $78.1 \pm 23.1(70.5)$ & $71.2 \pm 22.5(74.5)$ \\
\hline LSI $<90 \%$ & $88.4 \pm 13.0(65.8)$ & $82.3 \pm 16.0(92.8)$ & $93.8 \pm 11.1(42.6)$ & $72.1 \pm 25.1(58.9)$ & $66.7 \pm 22.9(66.4)$ \\
\hline \multicolumn{6}{|l|}{ Isokinetic hamstring strength } \\
\hline $\mathrm{LSI} \geq 90 \%$ & $89.4 \pm 13.0(70.4)$ & $83.4 \pm 15.9(93.2)$ & $94.7 \pm 10.9(47.7)$ & $75.5 \pm 24.3(65.2)$ & $69.0 \pm 23.0(70.7)$ \\
\hline LSI $<90 \%$ & $88.7 \pm 13.0(66.3)$ & $83.2 \pm 15.5(93.9)$ & $94.0 \pm 10.4(43.6)$ & $72.8 \pm 24.8(60.3)$ & $67.4 \pm 22.8(67.5)$ \\
\hline \multicolumn{6}{|l|}{ Single-leg-hop test } \\
\hline $\mathrm{LSI} \geq 90 \%$ & $90.0 \pm 12.0(70.6)$ & $84.1 \pm 15.5(94.4)$ & $95.5 \pm 8.9(49.5)$ & $77.5 \pm 22.4(67.7)$ & $70.2 \pm 22.3(72.1)$ \\
\hline LSI $<90 \%$ & $87.7 \pm 14.0(65.1)$ & $82.1 \pm 15.9(92.6)$ & $92.9 \pm 12.5(40.2)$ & $69.6 \pm 26.6(55.9)$ & $65.3 \pm 23.2(64.9)$ \\
\hline
\end{tabular}

KOOS Knee injury and Osteoarthritis Outcome Score; PASS patient-acceptable symptom state; $A D L$ activities of daily living; $Q o L$ quality of life; $S D$ standard deviation; $H T$ hamstring tendon; BPTB bone-patellar tendon bone; LSI limb symmetry index

(LSI $\geq 90 \%$ ) 6-month isokinetic quadriceps and hamstring strength and single-leg-hop test performance, was taken into account in our study. These three factors were included as separate dependent variables in our multivariate logistic regression analysis. Nevertheless, our results showed that female gender is a factor that is per se negatively associated with the achievement of a PASS on the KOOS Pain, ADL, and Sport and Recreation subscales 2 years after primary
ACLR. It is not clear why female patients report poorer subjective knee outcomes. A recent systematic review and metaanalysis [42], including a total of 135 publications with more than 120.000 patients, revealed that females report poorer subjective outcomes than males after ACLR. However, no difference was found in any objective parameter.

One unanticipated result was that a longer ( $>3$ months) time interval from injury to surgery per se had no effect 
Table 3 Factors affecting the achievement of a PASS on the KOOS pain $(\geq 88.9)$ subscale
Table 4 Factors affecting the achievement of a PASS on the KOOS Symptoms $(\geq 57.1)$ subscale

\begin{tabular}{lcccc}
\hline Factor & $\begin{array}{l}\text { Regression coef- } \\
\text { ficient (ß) }\end{array}$ & SE & OR $(95 \%$ CI $)$ & $P$ value \\
\hline Pre-operative & & & & \\
Age $\geq 30$ years & 0.43 & 0.11 & $1.54(1.23-1.92)$ & $<0.001^{*}$ \\
Female gender & -0.26 & 0.10 & $0.76(0.62-0.94)$ & $0.01^{*}$ \\
Delayed (>3 months) ACLR & 0.04 & 0.13 & $1.04(0.80-1.36)$ & n.s. \\
Pre-injury Tegner activity level $\geq 6$ & -0.01 & 0.16 & $0.98(0.71-1.36)$ & n.s. \\
Intra-operative & & & & \\
HT autograft & 0.29 & 0.21 & $1.34(0.88-2.05)$ & n.s. \\
MM resection & 0.18 & 0.15 & $1.19(0.88-1.62)$ & n.s. \\
MM repair & -0.52 & 0.24 & $0.59(0.36-0.96)$ & $0.03^{*}$ \\
LM resection & -0.11 & 0.14 & $0.88(0.66-1.18)$ & n.s. \\
LM repair & 0.21 & 0.30 & $1.23(0.68-2.24)$ & n.s. \\
Cartilage injury & 0.05 & 0.14 & $1.00(0.76-1.32)$ & n.s. \\
Post-operative (6 months) & & & & \\
Quadriceps strength LSI $\geq 90 \%$ & 0.30 & 0.11 & $1.35(1.08-1.70)$ & $0.009^{*}$ \\
Hamstring strength LSI $\geq 90 \%$ & -0.02 & 0.10 & $0.97(0.79-1.20)$ & n.s. \\
Single-leg-hop test LSI $\geq 90 \%$ & 0.14 & 0.11 & $1.15(0.92-1.44)$ & n.s. \\
\hline
\end{tabular}

PASS Patient-acceptable symptom state; KOOS Knee injury and Osteoarthritis Outcome Score; ACLR anterior cruciate ligament reconstruction; $H T$ hamstring tendon; $M M$ medial meniscus; $L M$ lateral meniscus; $L S I$ limb symmetry index; $S E$ standard error; $O R$ odds ratio; $C I$ confidence interval

*Statistically significant. $P$ value $<0.05$

\begin{tabular}{lcccc}
\hline Factor & $\begin{array}{l}\text { Regression coef- } \\
\text { ficient (B) }\end{array}$ & SE & OR (95\% CI) & $P$ value \\
\hline Pre-operative & & & & \\
Age $\geq 30$ years & 0.52 & 0.23 & $1.68(1.06-2.67)$ & $0.02^{*}$ \\
Female gender & -0.07 & 0.20 & $0.92(0.61-1.39)$ & n.s. \\
Delayed (>3 months) ACLR & 0.23 & 0.24 & $1.26(0.78-2.05)$ & n.s. \\
Pre-injury Tegner activity level $\geq 6$ & -0.24 & 0.36 & $0.78(0.37-1.61)$ & n.s. \\
Intra-operative & & & & \\
HT autograft & 0.30 & 0.36 & $1.35(0.66-2.78)$ & n.s. \\
MM resection & 0.72 & 0.40 & $2.06(0.93-4.56)$ & n.s. \\
MM repair & -0.22 & 0.42 & $0.79(0.34-1.84)$ & n.s. \\
LM resection & -0.39 & 0.27 & $0.67(0.39-1.14)$ & n.s. \\
LM repair & -0.49 & 0.46 & $0.60(0.24-1.51)$ & n.s. \\
Cartilage injury & 0.16 & 0.29 & $1.81(0.65-2.12)$ & n.s. \\
Post-operative (6 months) & & & & \\
Quadriceps strength LSI $\geq 90 \%$ & 0.48 & 0.24 & $1.62(1.00-2.63)$ & $0.04 *$ \\
Hamstring strength LSI $\geq 90 \%$ & -0.19 & 0.21 & $0.82(0.54-1.24)$ & n.s. \\
Single-leg-hop test LSI $\geq 90 \%$ & 0.34 & 0.22 & $1.41(0.91-2.17)$ & n.s. \\
\hline
\end{tabular}

PASS Patient-acceptable symptom state; KOOS Knee injury and Osteoarthritis Outcome Score; ACLR anterior cruciate ligament reconstruction; $H T$ hamstring tendon; $M M$ medial meniscus; $L M$ lateral meniscus; $L S I$ limb symmetry index; $S E$ standard error; $O R$ odds ratio; $C I$ confidence interval

*Statistically significant. $P$ value $<0.05$ on the achievement of a PASS on any of the KOOS subscale. Several studies have suggested potential benefits from attempting to shorten the time span between injury and ACLR $[19,45]$. A longer waiting time from injury to surgery may increase the risk of additional cartilage and medial meniscus injuries in the ACL-deficient knee [3]. However, it is possible that delayed surgery per se does not impact subjective knee outcome after ACLR, unless recurrent giving ways with subsequent meniscal or cartilage injuries occur. 
Table 5 Factors affecting the achievement of a PASS on the KOOS ADL (=100.0) subscale

\begin{tabular}{lcccc}
\hline Factor & $\begin{array}{l}\text { Regression coef- } \\
\text { ficient (B) }\end{array}$ & SE & OR (95\% CI) & $P$ value \\
\hline Pre-operative & & & & \\
Age $\geq 30$ years & 0.32 & 0.11 & $1.37(1.10-1.71)$ & $0.004^{*}$ \\
Female gender & -0.23 & 0.10 & $0.79(0.64-0.97)$ & $0.02^{*}$ \\
Delayed (>3 months) ACLR & 0.20 & 0.13 & $0.81(0.62-1.06)$ & n.s. \\
Pre-injury Tegner activity level $\geq 6$ & 0.02 & 0.16 & $1.00(0.72-1.38)$ & n.s. \\
Intra-operative & & & & \\
HT autograft & 0.01 & 0.21 & $1.01(0.66-1.55)$ & n.s. \\
MM resection & 0.19 & 0.14 & $1.21(0.90-1.61)$ & n.s. \\
MM repair & -0.20 & 0.25 & $0.81(0.49-1.33)$ & n.s. \\
LM resection & -0.20 & 0.14 & $0.81(0.61-1.08)$ & n.s. \\
LM repair & 0.47 & 0.29 & $1.60(0.89-2.86)$ & n.s. \\
Cartilage injury & -0.12 & 0.13 & $0.88(0.67-1.15)$ & n.s. \\
Post-operative (6 months) & & & & \\
Quadriceps strength LSI $\geq 90 \%$ & 0.29 & 0.11 & $1.34(1.07-1.67)$ & $0.01^{*}$ \\
Hamstring strength LSI $\geq 90 \%$ & -0.03 & 0.10 & $0.97(0.79-1.19)$ & n.s. \\
Single-leg-hop test LSI $\geq 90 \%$ & 0.31 & 0.11 & $1.37(1.09-1.71)$ & $0.005^{*}$ \\
\hline
\end{tabular}

PASS Patient-acceptable symptom state; KOOS Knee injury and Osteoarthritis Outcome Score; $A D L$ activities of daily living; $A C L R$ anterior cruciate ligament reconstruction; $H T$ hamstring tendon; $M M$ medial meniscus; $L M$ lateral meniscus; $L S I$ limb symmetry index; $S E$ standard error; OR odds ratio; $C I$ confidence interval

*Statistically significant. $P$ value $<0.05$

\begin{tabular}{lcccl}
\hline Factor & $\begin{array}{l}\text { Regression coef- } \\
\text { ficient (B) }\end{array}$ & SE & OR (95\% CI) & $P$ value \\
\hline Pre-operative & & & & \\
Age $\geq 30$ years & 0.41 & 0.11 & $1.52(1.20-1.91)$ & $<0.001^{*}$ \\
Female gender & -0.32 & 0.11 & $0.72(0.58-0.89)$ & $0.003^{*}$ \\
Delayed (>3 months) ACLR & -0.15 & 0.14 & $0.86(0.64-1.14)$ & n.s. \\
Pre-injury Tegner activity level $\geq 6$ & -0.30 & 0.17 & $0.73(0.52-1.04)$ & n.s. \\
Intra-operative & & & & \\
HT autograft & 0.70 & 0.21 & $2.02(1.31-3.10)$ & $0.001^{*}$ \\
MM resection & 0.13 & 0.16 & $1.14(0.83-1.57)$ & n.s. \\
MM repair & -0.18 & 0.25 & $0.82(0.50-1.36)$ & n.s. \\
LM resection & -0.04 & 0.15 & $0.96(0.70-1.30)$ & n.s. \\
LM repair & 0.36 & 0.32 & $1.44(0.76-2.70)$ & n.s. \\
Cartilage injury & -0.30 & 0.14 & $0.73(0.55-0.97)$ & $0.03^{*}$ \\
Post-operative (6 months) & & & & \\
Quadriceps strength LSI $\geq 90 \%$ & 0.41 & 0.12 & $1.51(1.18-1.92)$ & $0.001^{*}$ \\
Hamstring strength LSI $\geq 90 \%$ & 0.06 & 0.11 & $1.06(0.85-1.32)$ & n.s. \\
Single-leg-hop test LSI $\geq 90 \%$ & 0.34 & 0.11 & $1.40(1.11-1.77)$ & $0.004^{*}$ \\
\hline
\end{tabular}

PASS Patient-acceptable symptom state; KOOS Knee injury and Osteoarthritis Outcome Score; ACLR anterior cruciate ligament reconstruction; $H T$ hamstring tendon; $M M$ medial meniscus; $L M$ lateral meniscus; $L S I$ limb symmetry index; $S E$ standard error; $O R$ odds ratio; $C I$ confidence interval

*Statistically significant. $P$ value $<0.05$
The use of HT autograft rather than BPTB autograft was associated with increased odds of achieving a PASS on the KOOS Sport and Recreation subscale. This difference between the grafts could be explained by the "donor-site morbidity" associated with the BPTB autograft $[5,8,10,24$, 46]. In a large cohort study based on the Swedish national knee ligament registry, Barenius et al. [3] showed that the 
Table 7 Factors affecting the achievement of a PASS on the KOOS QoL $(\geq 62.5)$ subscale

\begin{tabular}{lcccc}
\hline Factor & $\begin{array}{l}\text { Regression coef- } \\
\text { ficient (B) }\end{array}$ & SE & OR (95\% CI) & $P$ value \\
\hline Pre-operative & & & & \\
Age $\geq 30$ years & 0.82 & 0.12 & $2.28(1.78-2.92)$ & $<0.001^{*}$ \\
Female gender & -0.13 & 0.11 & $0.87(0.69-1.09)$ & n.s. \\
Delayed (>3 months) ACLR & -0.09 & 0.14 & $0.90(0.67-1.21)$ & n.s. \\
Pre-injury Tegner activity level $\geq 6$ & -0.08 & 0.18 & $0.91(0.63-1.31)$ & n.s. \\
Intra-operative & & & & \\
HT autograft & 0.25 & 0.22 & $1.29(0.82-2.01)$ & n.s. \\
MM resection & -0.09 & 0.16 & $0.99(0.71-1.38)$ & n.s. \\
MM repair & -0.38 & 0.25 & $0.68(0.41-1.12)$ & n.s. \\
LM resection & 0.06 & 0.16 & $1.06(0.77-1.47)$ & n.s. \\
LM repair & 0.25 & 0.32 & $1.28(0.67-2.43)$ & n.s. \\
Cartilage injury & -0.01 & 0.15 & $0.98(0.72-1.32)$ & n.s. \\
Post-operative (6 months) & & & & \\
Quadriceps strength LSI $\geq 90 \%$ & 0.39 & 0.12 & $1.48(1.15-1.91)$ & $0.002^{*}$ \\
Hamstring strength LSI $\geq 90 \%$ & 0.02 & 0.11 & $1.02(0.81-1.28)$ & n.s. \\
Single-leg-hop test LSI $\geq 90 \%$ & 0.24 & 0.12 & $1.28(1.00-1.63)$ & $0.04^{*}$ \\
\hline
\end{tabular}

PASS Patient-acceptable symptom state; KOOS Knee injury and Osteoarthritis Outcome Score; QoL quality of life; $A C L R$ anterior cruciate ligament reconstruction; $H T$ hamstring tendon; $M M$ medial meniscus; $L M$ lateral meniscus; $L S I$ limb symmetry index; $S E$ standard error; $O R$ odds ratio; $C I$ confidence interval

*Statistically significant. $P$ value $<0.05$ use of BPTB autograft is a negative predictor of functional recovery 2 years after ACLR.

Interestingly, neither MM nor LM resection affected the achievement of a PASS on any of the KOOS subscales 2 years after primary ACLR. However, it is known that a concurrent meniscal resection may negatively affect the long-term outcomes after ACLR [4, 6, 28, 38, 40]. Similarly, in the present study, the presence of a cartilage injury at the time of primary ACLR only weakly affected $(P=0.03)$ the achievement of a PASS on the Sport and Recreation KOOS subscale at the 2-year follow-up. No correlation between the presence of a cartilage injury and the achievement of a PASS on any of the other KOOS subscales was found. Nevertheless, the association between cartilage injury and an inferior KOOS on several subscales at a long-term follow-up has been previously established [7, 14, 33]. Perhaps, a 2-year follow-up is too early to see the reported poorer long-term outcomes related to meniscal resection or the presence of a cartilage injury. The consequences of losing meniscal tissue on subjective knee function may not be appreciated until repetitive loading on the knee occurs over the course of several years after ACLR [22]. The same consideration could be applied to cartilage injuries, with symptoms that may not be revealed in the first few years after ACLR.

The presence of a concomitant MM repair reduced the odds of achieving a PASS on the KOOS Pain subscale. Few recent studies $[22,30,41]$ have attempted to clarify the effects of concomitant meniscal resection or repair on postoperative outcomes after ACLR at a short-term follow-up.
Svantesson et al. [41] reported that patients with meniscal repair have poorer subjective knee function, measured with the Lysholm and KOOS, at both the 6- and the 12-month follow-up after ACLR. LaPrade et al. [22] reported that the 2-year post-operative KOOS in patients with MM resection, LM resection or LM repair did not differ significantly from an isolated ACLR for any of the five KOOS subscales. On the other hand, the results after an MM repair were significantly inferior for the Symptoms and QoL KOOS subscales. It has been suggested [22] that the decreased mobility of the MM in comparison with the LM and the different insertion geometries of the medial and lateral meniscus roots [18, 23, 45] may explain the better outcomes for LM repair in comparison with MM repair after ACLR at a short-term follow-up.

The recovery of symmetrical isokinetic quadriceps and hamstring strength and single-leg-hop test performance is regarded as a key factor prior to return to sport after ACLR. Muscular and functional asymmetries are known to be risk factors for ACL graft tears and knee re-injuries [11, 15, 21]. However, only a few studies [17, 25, 39] have attempted to analyse the effects of muscular strength and hop performance on longitudinal subjective knee outcome after ACLR. In the present study, the recovery of 6-month symmetrical isokinetic quadriceps strength consistently increased the odds of achieving a PASS on all the KOOS subscales and a symmetrical 6-month single-leg-hop test performance increased the odds of achieving a PASS on the ADL, Sport and Recreation, and QoL subscales 2 years after ACLR. 
Among all the modifiable factors studied, the results of these tests had the greatest effect on predicting the achievement of a PASS on the different KOOS subscales 2 years after ACLR. Conducting these tests 6 months after ACLR could, therefore, be appropriate for predictive purposes, as they can be used to inform the clinician about the patient's likely prognosis and the need for targeted rehabilitation to address strength and hop asymmetries and improve subjective knee function, promoting the achievement of a PASS after ACLR.

The results of the present study have significant implications for the clinical management of patients after primary ACLR. This is, to our knowledge, the first large cohort study assessing the percentage of patients achieving an acceptable symptom state 2 years after primary ACLR. In addition, it provides unique data, comprising a detailed analysis of patient pre-operative, intra-operative and post-operative factors affecting the achievement of a PASS 2 years after primary ACLR. To improve treatment outcome after ACLR and assess individual expected outcome, a large spectrum of potential factors affecting subjective knee outcome must be simultaneously evaluated [26]. Some key factors, like age and gender, are non-modifiable. However, an awareness of the effect of these factors on the achievement of a PASS could help clinicians to counsel patients about their expectations after ACLR. On the other hand, most of the surgery- and rehabilitation-related factors are modifiable. The knowledge of these modifiable factors should, therefore, be used by clinicians and physical therapists to improve subjective knee function and maximise the achievement of a PASS after primary ACLR.

The main strength of this study is the analysis of a large cohort (2335 patients). This enabled a robust logistic regression analysis and a detailed, comprehensive evaluation of several factors affecting the achievement of a PASS after primary ACLR that have not been investigated in the previous studies. The study cohort represented a wide range of patients in terms of age, time from injury to surgery, preinjury activity level, and concomitant meniscal surgery. The results of this study are, therefore, highly generalizable. All the patients received standardised surgery, rehabilitation, and post-operative assessment at the same institution. Finally, this study analysed the results of the KOOS after ACLR in a clinically meaningful way. The achievement of a PASS is known to correlate with the patient's perception of treatment [27].

The main limitation is the suboptimal follow-up. Only $48.7 \%$ of the patients had filled in the KOOS questionnaires 2 years post-operatively. The loss of approximately $51 \%$ of patients due to missing 2-year KOOS values is not ideal, but this follow-up rate is in line with the previous large cohort studies $[2,20]$. The patients lost to follow-up tended to be younger and with a larger proportion of men than women in the included cohort. This phenomenon has previously been described in a non-response analysis of 2-year data in the Swedish national knee ligament registry [32]. Differences between the patients included and lost to follow-up, in terms of age and gender, may have the potential for selection bias and could have influenced the results. However, with the exception of age and gender, all the other patient characteristics were comparable between the included cohort and the cohort lost to follow-up. The lack of details regarding the depth and location of cartilage injuries is a limitation. Røtterud et al. [36] found no significant associations between partial-thickness cartilage lesions and the scores on any of the KOOS subscales at the 2-year follow-up. On the other hand, full-thickness cartilage lesions were significantly associated with reduced scores on all the KOOS subscales. It is possible that the dichotomization of cartilage injury to "yes" or "no" in our study has acted as a confounder for predicting the achievement of a PASS after ACLR. The same consideration could be applied to meniscal resections. Unfortunately, information regarding the size and location of meniscal resections was not available. It could be hypothesised that larger resections have a greater impact on PROs at follow-up.

\section{Conclusion}

More than $60 \%$ of the patients reported an acceptable symptom state on four of the five KOOS subscales 2 years after primary ACLR. Age $\geq 30$ years and female gender were the non-modifiable factors that consistently increased and reduced, respectively, the odds of achieving a PASS. Symmetrical 6-month isokinetic quadriceps strength and singleleg-hop test performance were the modifiable factors that consistently increased the opportunity of achieving a PASS 2 years after primary ACLR.

Acknowledgements The authors would like to thank the Capio Research Foundation, the Sophiahemmet Research Foundation, and the Eva \& Oscar Ahréns stiftelse for the support received.

Funding This study received funding for study purpose from the Capio research foundation, the Sophiahemmet research foundation and the Eva \& Oscar Ahréns stiftelse.

\section{Compliance with ethical standards}

Conflict of interest Each author declares that no possible conflict of interest (financial or not financial) exist in connection with this study.

Ethical approval This study was approved from the Regional Ethics Committee, Karolinska Institutet, Diarie number: 2016/1613-31/2.

Informed consent For this type of study, formal consent is not required. 
Open Access This article is distributed under the terms of the Creative Commons Attribution 4.0 International License (http://creativeco mmons.org/licenses/by/4.0/), which permits unrestricted use, distribution, and reproduction in any medium, provided you give appropriate credit to the original author(s) and the source, provide a link to the Creative Commons license, and indicate if changes were made.

\section{References}

1. Ageberg E, Forssblad M, Herbertsson P, Roos EM (2010) Sex differences in patient-reported outcomes after anterior cruciate ligament reconstruction: data from the Swedish knee ligament register. Am J Sports Med 38(7):1334-1342

2. Ahldén M, Samuelsson K, Sernert N, Forssblad M, Karlsson J, Kartus J (2012) The Swedish national anterior cruciate ligament register: a report on baseline variables and outcomes of surgery for almost 18,000 patients. Am J Sports Med 40(10):2230-2235

3. Barenius B, Forssblad M, Engström B, Eriksson K (2013) Functional recovery after anterior cruciate ligament reconstruction, a study of health-related quality of life based on the Swedish National Knee Ligament Register. Knee Surg Sports Traumatol Arthrosc 21(4):914-927

4. Barenius B, Ponzer S, Shalabi A, Bujak R, Norlén L, Eriksson K (2014) Increased risk of osteoarthritis after anterior cruciate ligament reconstruction: a 14-year follow-up study of a randomized controlled trial. Am J Sports Med 42(5):1049-1057

5. Carmichael JR, Cross MJ (2009) Why bone-patella tendon-bone grafts should still be considered the gold standard for anterior cruciate ligament reconstruction. Br J Sports Med 43(5):323-325

6. Claes S, Hermie L, Verdonk R, Bellemans J, Verdonk P (2013) Is osteoarthritis an inevitable consequence of anterior cruciate ligament reconstruction? A meta-analysis. Knee Surg Sports Traumatol Arthrosc 21(9):1967-1976

7. Cox CL, Huston LJ, Dunn WR et al (2014) Are articular cartilage lesions and meniscus tears predictive of IKDC, KOOS, and MarX activity level outcomes after anterior cruciate ligament reconstruction? A 6-year multicenter cohort study. Am J Sports Med 42(5):1058-1067

8. Cristiani R, Sarakatsianos V, Engström B, Samuelsson K, Forssblad M, Stålman A (2019) Increased knee laxity with hamstring tendon autograft compared to patellar tendon autograft: a cohort study of 5462 patients with primary anterior cruciate ligament reconstruction. Knee Surg Sports Traumatol Arthrosc 27(2):381-388

9. Desai N, Björnsson H, Samuelsson K, Karlsson J, Forssblad M (2014) Outcomes after ACL reconstruction with focus on older patients: results from the Swedish national anterior cruciate ligament register. Knee Surg Sports Traumatol Arthrosc 22(2):379-386

10. Feller JA, Webster KE (2003) A randomized comparison of patellar tendon and hamstring tendon anterior cruciate ligament reconstruction. Am J Sports Med 31(4):564-573

11. Grindem H, Snyder-Mackler L, Moksnes H, Engebretsen Risberg MA (2016) Simple decision rules can reduce reinjury risk by $84 \%$ after ACL reconstruction: the Delaware-Oslo ACL cohort study. Br J Sports Med 50:804-808

12. Hamrin Senorski E, Svantesson E, Beischer S, Grassi A, Krupic F, Thomeé R, Samuelsson K (2018) Factors affecting the achievement of a patient-acceptable symptom state 1 year after anterior cruciate ligament reconstruction: a cohort study of 343 patients from 2 registries. Orthop J Sports Med 6(4):2325967118764317

13. Hamrin Senorski E, Svantesson E, Beischer S, Thomeé C, Grassi A, Krupic F, Thomeé R, Karlsson J, Samuelsson K (2018)
Concomitant injuries may not reduce the likelihood of achieving symmetrical muscle function one year after anterior cruciate ligament reconstruction: a prospective observational study based on 263 patients. Knee Surg Sports Traumatol Arthrosc 26(10):2966-2977

14. Hamrin Senorski E, Svantesson E, Spindler KP, Alentorn-Geli E, Sundemo D, Westin O, Karlsson J, Samuelsson K (2018) Ten-year risk factors for inferior knee injury and osteoarthritis outcome score after anterior cruciate ligament reconstruction: a study of 874 patients from the Swedish national knee ligament register. Am J Sports Med 46(12):2851-2858

15. Hiemstra LA, Webber S, MacDonald PB, Kriellaars DJ (2007) Contralateral limb strength deficits after anterior cruciate ligament reconstruction using a hamstring tendon graft. Clin Biomech (Bristol, Avon) 22:543-550

16. Ingelsrud LH, Granan LP, Terwee CB, Engebretsen L, Roos EM (2015) Proportion of patients reporting acceptable symptoms or treatment failure and their associated KOOS values at 6 to 24 months after anterior cruciate ligament reconstruction: a study from the Norwegian knee ligament registry. Am J Sports Med 43(8):1902-1907

17. Ithurburn MP, Altenburger AR, Thomas S, Hewett TE, Paterno MV, Schmitt LC (2018) Young athletes after ACL reconstruction with quadriceps strength asymmetry at the time of return-tosport demonstrate decreased knee function 1 year later. Knee Surg Sports Traumatol Arthrosc 26(2):426-433

18. Johannsen AM, Civitarese DM, Padalecki JR, Goldsmith MT, Wijdicks CA, LaPrade RF (2012) Qualitative and quantitative anatomic analysis of the posterior root attachments of the medial and lateral menisci. Am J Sports Med 40(10):2342-2347

19. Karlsson J, Kartus J, Magnusson L, Larsson J, Brandsson S, Eriksson BI (1999) Subacute versus delayed reconstruction of the anterior cruciate ligament in the competitive athlete. Knee Surg Sports Traumatol Arthrosc 7(3):146-151

20. Kvist J, Kartus J, Karlsson J, Forssblad M (2014) Results from the Swedish national anterior cruciate ligament register. Arthroscopy 30(7):803-810

21. Kyritsis P, Bahr R, Landreau P, Miladi R, Witvrouw E (2016) Likelihood of ACL graft rupture: not meeting six clinical discharge criteria before return to sport is associated with a four times greater risk of rupture. Br J Sports Med 50:946-951

22. LaPrade CM, Dornan GJ, Granan LP, LaPrade RF, Engebretsen L (2015) Outcomes after anterior cruciate ligament reconstruction using the Norwegian knee ligament registry of 4691 patients: how does meniscal repair or resection affect short-term outcomes? Am J Sports Med 43(7):1591-1597

23. LaPrade CM, Ellman MB, Rasmussen MT, James EW, Wijdicks CA, Engebretsen L, LaPrade RF (2014) Anatomy of the anterior root attachments of the medial and lateral menisci: a quantitative analysis. Am J Sports Med 42(10):2386-2392

24. Li S, Su W, Zhao J, Xu Y, Bo Z, Ding X, Wei Q (2011) A metaanalysis of hamstring autografts versus bone-patellar tendon-bone autografts for reconstruction of the anterior cruciate ligament. Knee 18(5):287-293

25. Logerstedt D, Grindem H, Lynch A, Eitzen I, Engebretsen L, Risberg MA, Axe MJ, Snyder-Mackler L (2012) Single-legged hop tests as predictors of self-reported knee function after anterior cruciate ligament reconstruction: the Delaware-Oslo ACL cohort study. Am J Sports Med 40(10):2348-2356

26. Magnussen RA, Verlage M, Flanigan DC, Kaeding CC, Spindler KP (2015) Patient-reported outcomes and their predictors at minimum 10 years after anterior cruciate ligament reconstruction: a systematic review of prospectively collected data. Orthop J Sports Med. 3(3):2325967115573706

27. Muller B, Yabroudi MA, Lynch A, Lai CL, van Dijk CN, Fu FH, Irrgang JJ (2016) Defining thresholds for the patient acceptable 
symptom state for the IKDC subjective knee form and KOOS for patients who underwent ACL reconstruction. Am J Sports Med 44(11):2820-2826

28. Pengas IP, Assiotis A, Nash W, Hatcher J, Banks J, McNicholas MJ (2012) Total meniscectomy in adolescents: a 40-year followup. J Bone Joint Surg Br 94(12):1649-1654

29. Petschnig R, Baron R, Albrecht M (1998) The relationship between isokinetic quadriceps strength test and hop tests for distance and one-legged vertical jump test following anterior cruciate ligament reconstruction. J Orthop Sports Phys Ther 28:23-31

30. Phillips M, Rönnblad E, Lopez-Rengstig L, Svantesson E, Stålman A, Eriksson K, Ayeni OR, Samuelsson K (2018) Meniscus repair with simultaneous ACL reconstruction demonstrated similar clinical outcomes as isolated ACL repair: a result not seen with meniscus resection. Knee Surg Sports Traumatol Arthrosc 26(8):2270-2277

31. Reid A, Birmingham TB, Stratford PW, Alcock GK, Giffin JR (2007) Hop testing provides a reliable and valid outcome measure during rehabilitation after anterior cruciate ligament reconstruction. Phys Ther 87(3):337-349

32. Reinholdsson J, Kraus-Schmitz J, Forssblad M, Edman G, Byttner M, Stålman A (2017) A non-response analysis of 2-year data in the Swedish Knee Ligament Register. Knee Surg Sports Traumatol Arthrosc 25(8):2481-2487

33. Risberg MA, Oiestad BE, Gunderson R et al (2016) Changes in knee osteoarthritis, symptoms, and function after anterior cruciate ligament reconstruction: a 20-year prospective follow-up study. Am J Sports Med 44(5):1215-1224

34. Roos EM, Roos HP, Lohmander LS, Ekdahl C, Beynnon BD (1998) Knee Injury and Osteoarthritis Outcome Score (KOOS): development of a self-administered outcome measure. J Orthop Sports Phys Ther 28(2):88-96

35. Ross MD, Langford B, Whelan PJ (2002) Test-retest reliability of 4 single-leg horizontal hop tests. J Strength Cond Res 16(4):617-622

36. Røtterud JH, Siversten EA, Forssblad M, Engebretsen L, Arøen A (2013) Effect of meniscal and focal cartilage lesions on patientreported outcome after anterior cruciate ligament reconstruction: a nationwide cohort study from Norway and Sweden of 8476 patients with 2-year follow-up. Am J Sports Med 41(3):535-543

37. Samuelsson K, Magnussen RA, Alentorn-Geli E, Krupic F, Spindler KP, Johansson C, Forssblad M, Karlsson J (2017) Equivalent knee injury and osteoarthritis outcome scores 12 and 24 months after anterior cruciate ligament reconstruction: results from the Swedish national knee ligament register. Am J Sports Med 45(9):2085-2091

38. Shelbourne KD, Gray T (2000) Results of anterior cruciate ligament reconstruction based on meniscus and articular cartilage status at the time of surgery: five- to fifteen-year evaluations. Am J Sports Med 28(4):446-452

39. Sousa PL, Krych AJ, Cates RA, Levy BA, Stuart MJ, Dahm DL (2017) Return to sport: does excellent 6-month strength and function following ACL reconstruction predict midterm outcomes? Knee Surg Sports Traumatol Arthrosc 25(5):1356-1363

40. Stein T, Mehling AP, Welsch F, von Eisenhart-Rothe R, Jäger A (2010) Long-term outcome after arthroscopic meniscal repair versus arthroscopic partial meniscectomy for traumatic meniscal tears. Am J Sports Med 38(8):1542-1548

41. Svantesson E, Cristiani R, Hamrin Senorski E, Forssblad M, Samuelsson K, Stålman A (2018) Meniscal repair results in inferior short-term outcomes compared with meniscal resection: a cohort study of 6398 patients with primary anterior cruciate ligament reconstruction. Knee Surg Sports Traumatol Arthrosc 26(8):2251-2258

42. Tan SH, Lau BP, Khin LW, Lingaraj K (2016) The importance of patient sex in the outcomes of anterior cruciate ligament reconstructions: a systematic review and meta-analysis. Am J Sports Med 44(1):242-254

43. Tegner Y, Lysholm J (1985) Rating systems in the evaluation of knee ligament injuries. Clin Orthop Relat Res 198:43-49

44. Thomeé R, Kaplan Y, Kvist J, Myklebust G, Risberg MA, Theisen D, Tsepis E, Werner S, Wondrasch B, Witvrouw E (2011) Muscle strength and hop performance criteria prior to return to sport after ACL reconstruction. Knee Surg Sports Traumatol Arthrosc 19(11):1798-1805

45. Thompson WO, Thaete FL, Fu FH, Dye SF (1991) Tibial meniscal dynamics using three-dimensional reconstruction of magnetic resonance images. Am J Sports Med 19(3):210-215

46. Xie X, Liu X, Chen Z, Yu Y, Peng S, Li Q (2015) A meta-analysis of bone-patellar-tendon-bone autograft versus four-strand hamstring tendon autograft for anterior cruciate ligament reconstruction. Knee 22(2):100-110

Publisher's Note Springer Nature remains neutral with regard to jurisdictional claims in published maps and institutional affiliations.

\section{Affiliations}

\section{Riccardo Cristiani ${ }^{1,2}(1) \cdot$ Christina Mikkelsen $^{1,2} \cdot$ Gunnar Edman $^{1} \cdot$ Magnus Forssblad $^{1} \cdot$ Björn Engström ${ }^{1,2} \cdot$ Anders Stålman ${ }^{1,2}$}

1 Department of Molecular Medicine and Surgery, Stockholm Sports Trauma Research Center, Karolinska Institutet, Stockholm, Sweden
2 Capio Artro Clinic, FIFA Medical Centre of Excellence, Sophiahemmet Hospital, Valhallavägen 91, 11486 Stockholm, Sweden 